\title{
APPLICATION OF QUANTITATIVE PROBABILISTIC RISK ASSESSMENT IN THE MINERALS INDUSTRY
}

\author{
T. Rasche ${ }^{1}$, M.L.Smith ${ }^{2}$, J.Joy $^{3}$ and T.Klinge ${ }^{4}$ \\ 1,2,3 MMME \\ University of Queensland, Australia \\ 1tilman.rasche@klinge.com.au \\ ${ }^{4}$ Klinge \& Co, Australia
}

\begin{abstract}
Probabilistic risk assessment has advantages over qualitative risk ranking for cases where choices need to be made that require consideration of variable inputs, where model sensitivities to variable inputs and their effects are to be studied, and where more detailed output is required to form the basis of sound and informed decision making. Monte Carlo Simulation and probability of failure prediction using First Order Reliability Methods (FORM) both provide this functionality and are used to both demonstrate the effects of variability on risk assessments for heat induced tyre failure, and to highlight the advantages of such a probabilistic approach.
\end{abstract}

\section{OPSOMMING}

Die probabilistiese assessering van risiko beskik oor bepaalde voordele vir gevalle waar keuses uitgeoefen moet word met onderliggende veranderlike insette, waar modelsensitiwiteit bepaal moet word vir inseteienskappe en die model gesonde en ingeligde besluitvorming moet ondersteun. Monte Carlo simulasie en eerste orde betroubaarheidsmetodes is daartoe instaat om die resultate te demonstreer oor hoe veranderlikheid risikoassessering beïnvloed by hittegeïnduseerde mislukkings van voertuigbande. 


\section{INTRODUCTION}

Over the past decade, the Australian minerals industry has pursued qualitative and semi-quantitative risk assessments with considerable success as evidenced by the gradual decrease in many safety related key performance indictors. The industry is now familiar with the use of techniques such as WRAC (Workplace Risk Assessment \& Control, [1]), HAZOP (hazard and operability study) and FMECA (failure mode, effect and criticality analysis). However, these qualitative techniques rely heavily on expert knowledge and are primarily only applied to plant subcomponents or equipment and are not very effective in assessing system hazards. None of these can effectively model stochastic input or the impact of uncertainty arising from the risk assessment methodology on the outcomes. Some quantitative methods, as used by other high risk industry sectors, can overcome these shortfalls and are ideal for applications where numeric data is available and where the inherent variability of the data should be considered before decisions on system safety and criticality are to be made.

\section{SOURCES OF VARIABILITY AND UNCERTAINTY}

All risk analysis methodologies must consider both the underlying variability of the inputs as well as uncertainties arising from the risk model itself. Both factors are widely acknowledged to have significant bearing on the decisions taken based on the risk assessment. Therefore, risk assessment methods that are able to handle variable input and reduce the uncertainties of the modelling process will be more realistic and better suited to make quality, defendable decisions.

\subsection{Variability}

Since the system being analysed in a risk assessment is a random process, variability will be introduced into a risk assessment. As a consequence, the results of a risk analysis will also exhibit variation that must be considered before an informed decision can be made. Some of the factors that affect the risk analysis are described below and shown in Figure 1. Often, considerable variability arises in the data as a result of local operating practices, environmental factors and maintenance routines. Where the risk assessment is based on locally gathered data, variability is likely to be introduced by the sampling methodology (less than adequate taxonomy or consideration on what type of data is collected), the technical means in which it is gathered (e.g. poor instrumentation) or the data analysis method itself (the statistics used to analyse the underlying distribution).

If a risk assessment is to be based on data from a database, additional caution needs to be applied. The availability of such data is generally sparse and extreme care in its application or adoption in other sectors is warranted in its use. For instance, while other high risk industries such as the nuclear, aerospace and petrochemical sectors have both developed outstanding database and related risk assessment data and methodologies (e.g. OREDA - Offshore Reliability database [2]) and use these with considerable success, the minerals industry globally still lacks such management tools. 


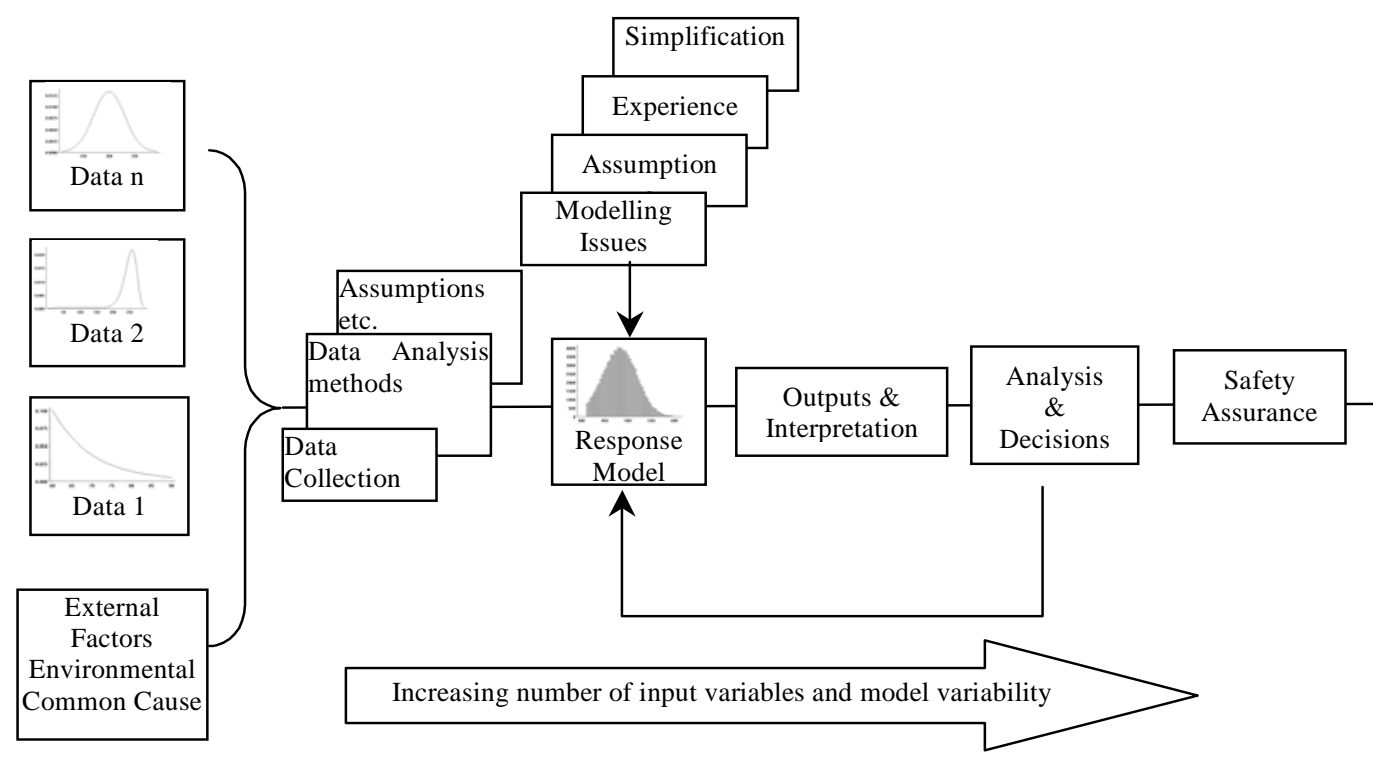

Figure 1: Variability in the inputs will create variable outputs

Additionally, published data may not be compatible with the characteristics that need to be reflected in the risk assessment scenario. It should also be pointed out that most databases assume a certain underlying distribution type, usually the exponential distribution, which may or may not be applicable to the specific situation that is being modelled. Extensive work by the author on failure data statistics of both fixed plant and mobile equipment has shown that the failure behavior of an item is often more accurately and more reliably characterized by distribution characteristics other than the exponential distribution.

\subsection{Uncertainty}

Benchmark studies such as by Amendola [3] and Holicky [4] have shown that considerable uncertainty, in contrast to variability, can be introduced into the risk assessment process through the choice of risk analysis model. While this choice may introduce some bias (e.g., lack of experience with a more suitable method), the risk analysis methodology will generate uncertainty and compromise the decision making process [5].

Empirical models can be very reliable in forecasting a specific (often only linear) behaviour, but larger and more comprehensive models (multidimensional and nonlinear) may become less reliable in their predictive capability. Many models also assume statistical independence between variables, which may not be the case.

A further complication is that many risk assessments deal with comparatively rare events for which little data is available and therefore often require application of specialised mathematical tools. Uncertainty is also introduced as the analyst tries to translate and combine physical parameters, dependencies and models into a combined mathematical relationship in an attempt to describe a system. Often 
generic scaling factors are used to 'calibrate' one model application to another, which inadvertently introduces uncertainty over the outcome.

This approach to risk analysis also assumes that the risk engineer is experienced at designing risk relationships based on quantitative models but given the variety of applications, it is clear that lack of familiarity with the application can introduce considerable scatter in the outcome.

One advantage of empirical models over any other approach to risk assessment is the ability to incorporate data that is based in statistical distributions and thereby accounting for data variability. Empirical models, by virtue of being explicit, also help in coming to a better understanding of model uncertainties.

Another factor that complicates the accuracy of any risk model is the effect that human interference (both in a positive and negative sense) can have on the behaviour of the system. The determination of human reliability is particularly challenging and to date no methodology has been proven to provide consistent and reliable human error forecasts.

\section{DIFFERENCES BETWEEN ASSESSMENTS}

In a qualitative or semi-quantitative assessment, risks are assessed relying solely on the experience of the team members, this implies that the make up and professional experience of the team will be reflected in the quality, reliability and recommendations of the assessment. Furthermore, if the given conditions, information and assumptions are not based on a familiar design, setting or scenario then additional variability is introduced into the assessment. Variability of any of the input parameters is implicit to the assessment and is rarely 'quantified'.

The main difficulty with either approach is the need to make an informed judgement about a rare event while accounting for the variability of all inputs and processes that affect the event being studied. Clearly, an assessment team's capability would be stretched if it were to provide an accurate and repeatable assessment about a known risk or had to make a judgement about two different designs, particularly if the team had limited experience with the new design. Furthermore, a team would have difficulty shedding any light on the sensitivity of the model to the input parameters or how the risk assessment outcome would change for different scenarios.

Quantitative models can be used to advantage where the data and its variability has been quantified as a statistical distribution and where the effects of the variability need to be studied in a more rigorous way. Such quantified assessments, often referred to as probabilistic, are routinely done in the nuclear and other hi-tech industries (for a current example, see [6]). There is no valid reason why the same methods cannot be applied in the minerals industry.

The following example of tyre failure demonstrates two methods of quantitative risk assessment and their application in probabilistic risk assessments. 


\subsection{Approach one - Application of Monte Carlo simulation (MCS) to study the risk of heat induced tyre failures}

MC simulation has been applied to a variety of areas where the variability of inputs and the effects on the system warrants study. Areas of application typically include engineering, health, environmental and financial analysis [7, 8]. MC is also a tried and tested tool in safety engineering as it provides the risk engineer not with just the risk magnitude (typically given as the expected or mean value in a deterministic analysis), but with the range of possible outcomes and therefore the likely distribution of the 'risk' under investigation. A further advantage of MCS is that it also allows the analyst to carry out detailed sensitivity studies searching for those input variables that have the greatest impact on the system behavior.

The example chosen is that of a large fleet of mining rear dump trucks which is utilised on a variety of haul routes. The study is based on a large database of tyre performance, including data on tread utilisation, payload, cycle time, failure mode description (reasons for removal) and tyre life. A preliminary analysis of 428 tyre failures is given in Figure 2, which shows that almost $71 \%$ of all tyres are scrapped with more that $50 \%$ of tread remaining. With earthmover costs as high as $A \$ 40,000$ per tyre and an increasing global tyre shortage, tyre life improvements achieving a higher tread utilization has the potential to add to the bottom line of mines.

Examination of the underlying failure modes is given in Figure 3 which shows that a large proportion ( 94\%) were caused by external factors such as inadequate road and pit floor maintenance with $27 \%$ of tyre failures associated with heat induced. While physical tyre damage can efficiently be reduced through improved road design, road maintenance activities and operator education, damage through heat requires a little more analysis.

Tyres have a limited resistance to build-up of heat and any excessive heat in the structure of a tyre can cause irreversible and destructive damage. Proactive tyre selection and ongoing evaluation of haulage conditions is therefore ideally done using a TKPH (tons kilometre per hour) approach which uses information of haulage length, vehicle velocity, ambient temperatures, vehicle tare weight and payload to predict heat of the tyre under operational conditions [9]. The effects that these variables have on the TKPH performance can be modelled by the following empirical relationship and equation.

$$
\begin{aligned}
& \text { TKPH }=\text { MeanTyre Load } * \text { Work Day Average Speed } \\
& \text { where }
\end{aligned}
$$

Mean Tyre Load in Ton = $($ Empty Mass in kg + Loaded Mass in kg $) /(2 * 1000)$

Work Day Average Speed $=($ Overall round trip length * Number Loads per Shift $) /$ Shift Hours 


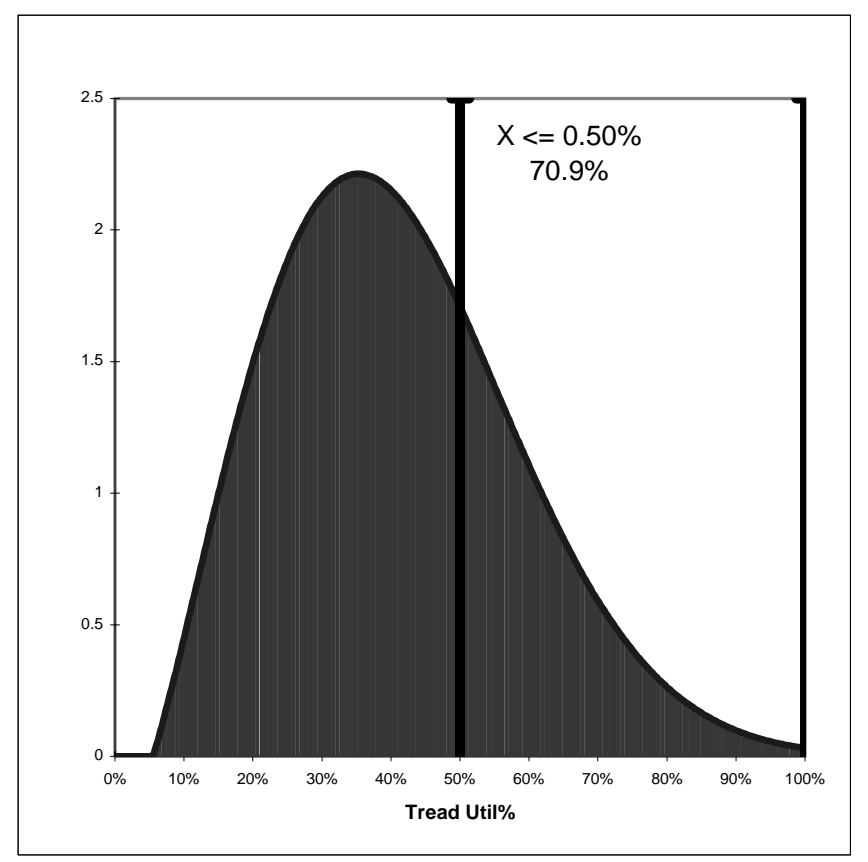

Figure 2: Histogram of percent tread utilisation.

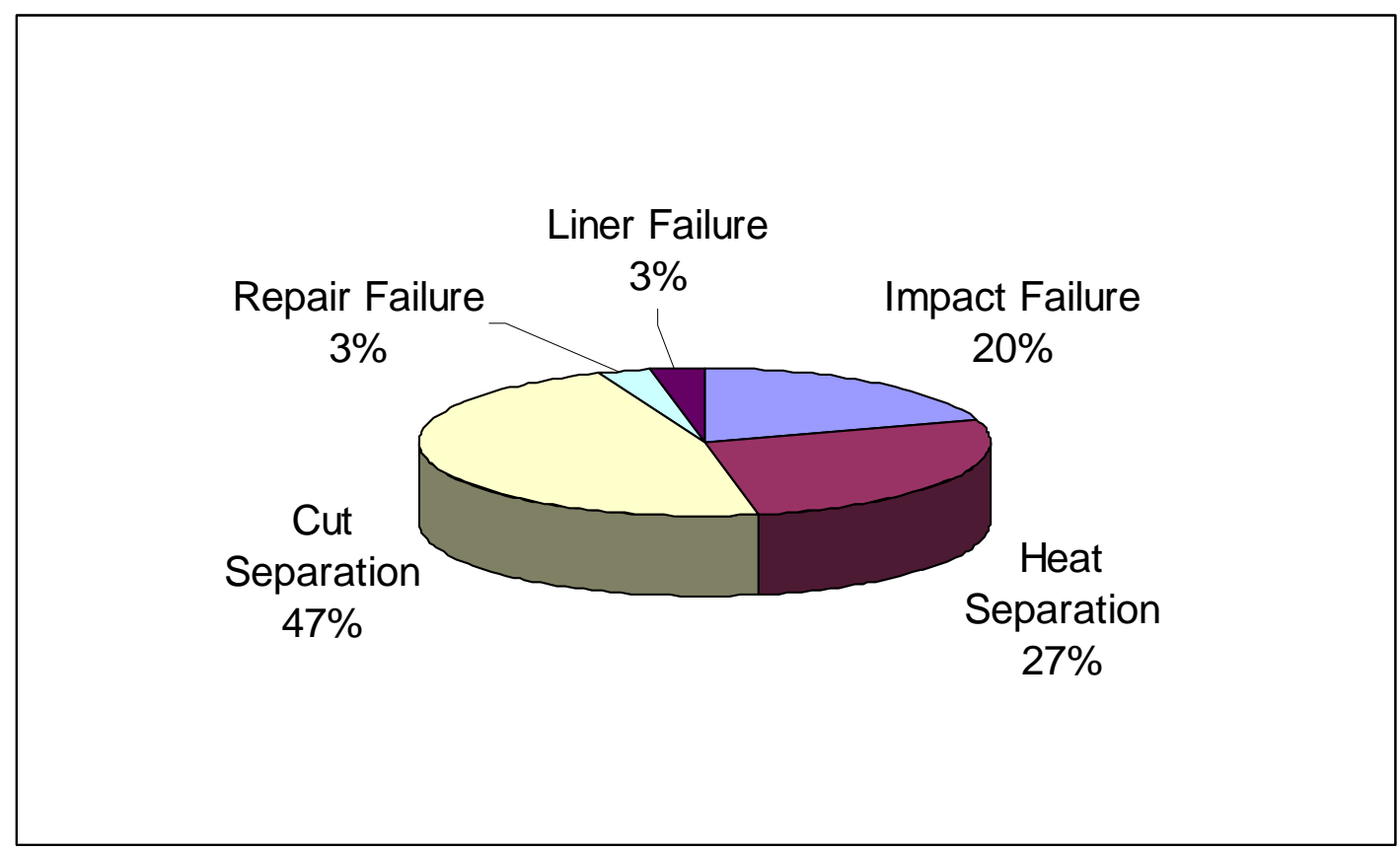

Figure 3: Main failure modes (tread utilisation < $50 \%$ ).

The statistical distribution characteristics and parameters (mean, standard deviation, possibly others to adequately describe distribution type) for truck speed, payload information, trip length, shift duration etc are firstly determined from the mines production recording system. The resultant TKPH distribution based on these inputs (Equation 1, see also Figure 4) is then established using the statistical distribution parameters and obtained through a crude Monte Carlo simulation utilizing a 
proprietary spreadsheet software add-ons such as @Risk, or Crystalball. The power of a Monte Carlo simulation is based on the repeated evaluation of, in this instance, Equation 1 with different inputs for speed, payload, distance and shift duration sampled from their individual data distributions during each recalculation. This has the effect that the inherent variability of the sets of input data is reflected in the evaluation, and by then plotting the resultant range of simulation outcomes, a realistic 'picture' of TKPH can be generated.

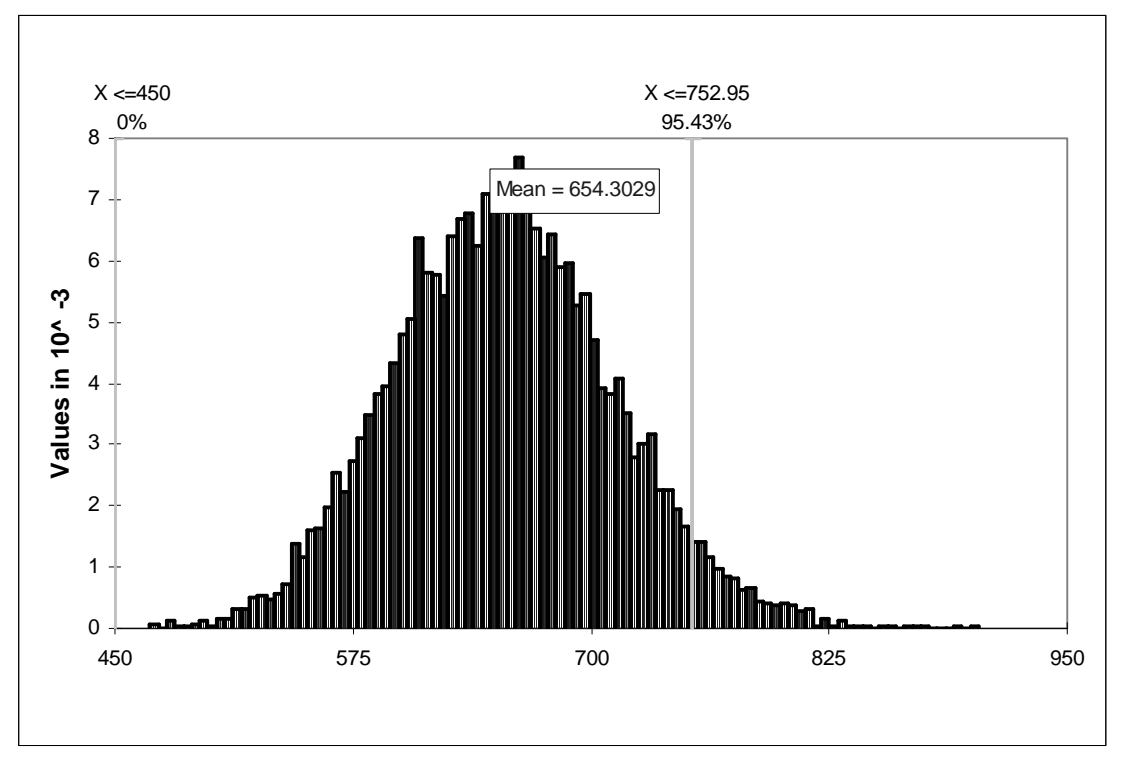

Figure 4: Histogram of Tyre TKPH.

The histogram in Figure 4 provides the results of 100,000 Monte Carlo simulations of TKPH responses of a mining haul truck tyre for a particular haul. In this case, the output of the simulation yields a normally distributed range of TKPH between 450 and 825 with an average actual TKPH of 654, which falls below the design TKPH of 755 (shown as the vertical bar in the figure ${ }^{1}$ ) giving the illusion, as would a classic deterministic analysis, that the tyre application was safe i.e. the limiting TKPH was not being exceeded during operation. However, examining the histogram of simulated TKPH in Figure 4, it can be seen that the limiting design TKPH is in fact exceeded on a number of occasions as indicated by the area under the curve to the right of the vertical bar (in this case 755). In the example, permissible TKPH is exceeded in $4.57 \%$ of all simulations, which translates to a heat induced loss of $4.6 \%$ on this particular haulage route ${ }^{2}$ or almost $17 \%$ of the overall tyre loss due to heat. While this basic analysis provides rapid understanding of which haulage applications contribute most to the overall loss, further sensitivity analysis can be carried out to provide insight into which variables have the greatest impact on TKPH exceedance and therefore require additional management. For instance, rather than opting for a more costly higher TKPH tyre to manage TKPH exceedance, mines usually choose

${ }^{1}$ Design TKPH values are provided by tyre manufacturers through technical documentation and handbooks.

${ }^{2}$ From Fig $4-95.43$ and $4.57 \%$ of the area under the graph lies below and above respectively the design TKPH design threshold of 755. 
to restrict haulage speed or payload, or a combination of both. As shown by this analysis, further investigation is warranted to cover the remaining mine haulage routes to further control heat induced tyre loss.

\subsection{Approach Two - First Order Reliability Methods}

First Order Reliability Methods (FORM) have their origins in structural engineering where they have found widespread application in determining risk levels to buildings and other civil engineering projects. Given FORMs versatility this method has been applied to pipeline, fire, marine design, corrosion and materials (fatigue) engineering [10-16]. Risk engineering in these fields often suffers from a lack of historical failure data which can be used to estimate the risk to a particular scenario.

FORM, like MC, overcomes this hurdle by allowing the engineer to model a particular failure mode through the creation of a safety margin equation that describes the interaction between the design strength or system capacity, R, and the load or demand, S, placed on the design. This relationship is expressed as

$M=R-S$

where $\mathrm{M}$ is the safety margin (analogous to a Factor of Safety) while R and S are representative of the system capacity and demand. Should the demand $S$ on the system be greater than its strength $\mathrm{R}$, failure will occur.

The likelihood of system failure $\mathrm{P}_{\mathrm{f}}$ can then symbolically be expressed as

$P_{f}=P(M \leq 0)=P\{(R-S) \leq 0\}$

where $P(M \leq 0)$ is the likelihood or probability that the safety margin $\mathrm{M}$ becomes or falls below zero. This concept is illustrated in Figure 5.

Both the capacity of the system and demand on the system are typically represented by random variables. Put simply, as long as the 'load demand' remains below the systems capacity the system can be deemed 'safe', It is possible that either 'demand' exceeds the systems capacity or that the 'capacity' itself drops below the demand generated by the system, in which case system failure occurs; these occurrences are shown as the shaded area under the capacity curve.

While Figure 5 uses bell-shaped curves to illustrate the natural variability of both capacity and demand of a system, it should be noted that the curves representing the variables could assume any shape other than 'Normal', depending on the underlying statistical behavior of the modeled systems. $\mathrm{R}$ and $\mathrm{S}$ can also assume deterministic values (as shown in Figure 4), rather than a variable; in the example an upper deterministic design TKPH limit is given that must not be exceeded for the system to remain safe. 


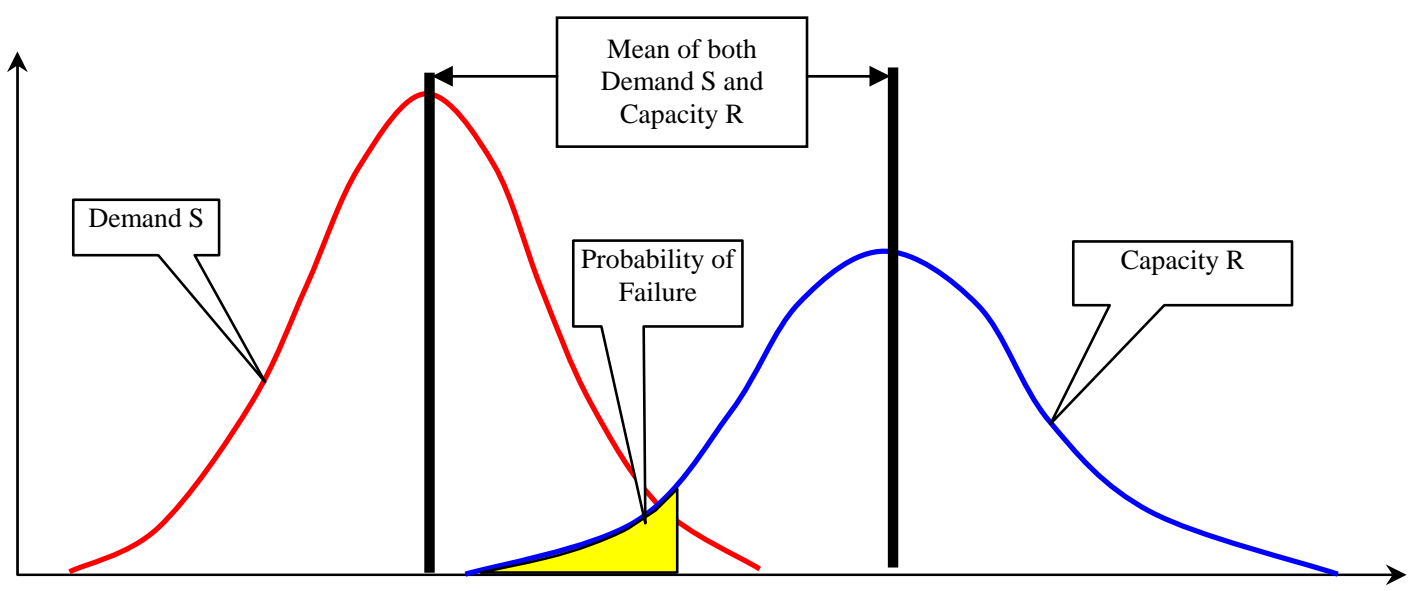

Figure 5: Capacity and Demand Representation of a Simple System

While MC simulation relies on a repeated calculation to yield a summary histogram of outcomes based on variable input, FORM uses a direct mathematical algorithm to evaluate the systems likelihood of failure. The particular advantage of FORM is that for capacity or demand equations that are functions of more than one variable (i.e. more than two dimensional and not necessarily Normal), FORM provides a completely general algorithm allowing solutions for all variables.

Application of FORM in conjunction with the same TKPH assessment as previously used provides an almost identical likelihood of failure, namely $4.7 \%$ for this particular haulage run.

However, a distinct advantage of FORM over MC simulation is the automatic calculation of the so called 'design points', which are those values (for each variable contained in the model) that cause the likelihood of failure for the system to exceed the set target thresholds for the system (in our example exceed the threshold target TKPH). For our example, the design points are given in Table 1.

\begin{tabular}{|l|c|c|}
\hline Variable Name & Design Point & Mean Estimate of Variable \\
\hline Loaded Mass (tonnes) & 100470 & 96020 \\
\hline Empty Mass (tonnes) & 65133 & 65010 \\
\hline Round trip length (km) & 8,13 & 7,5 \\
\hline Number of loads per shift & 27 & 26 \\
\hline Shift Hours & 7,97 & 8 \\
\hline
\end{tabular}

Table 1: Sample 'Design Point' Output

One obvious use for these results could be their application as individual threshold values or early warning indicators that are not to be exceeded if system safety is to be assured. 
For instance, as shown by the example, such design points could be utilised to nominate the maximum permissible payloads for a particular haulage run. For example, FORM predicts a likely TKPH exceedance once payloads of 100 tonnes are exceeded compared to a target load of 96 tonnes, provided all other inputs remain and other vehicle limits eg set by the manufacturer are not exceeded. Similarly, trip distance, which has considerable impact on heat generation in a tyre, must be maintained under $8 \mathrm{~km}$ etc.

No other technique allows the engineer to make judgements and reliable decisions in this way, which in this case could assist considerably with tyre safety, and reduce unnecessary tyre loss.

\section{CONCLUSION}

A quality risk assessment requires consideration of both the variability of the inputs as well as the uncertainties created by the modelling process itself. Qualitative methods are unable to account for stochastic input. Some quantitative methods and tools, such as Monte Carlo simulation and FORM, can account for stochastic input data. The consideration of even basic probabilistic analysis can highlight vulnerabilities of deterministic design (and decision making) and assist in risk mitigation protocols and safety management systems aimed at controlling risks to a set threshold.

As shown by the case study, the evaluation of tyre TKPH exceedance using MCS or FORM provides a better understanding of the tyres' behaviour and potential risk of failure compared to traditional deterministic evaluations. As mining equipment becomes larger and more productive resulting in tyres often working closer to their design limits, probabilistic approaches should be pursued to better forecast tyre failure risks, and the same techniques and tools should be used as decision making aids for the better management of other technical risks within the minerals industry.

\section{ACKNOWLEDGEMENTS}

The author would like to thank Dr. Markus Petschacher of Petschacher Consulting, Feldkirchen, Austria, for provision of his proprietary FORM software, VAP.

\section{REFERENCES}

[1] Liberty Risk Services, workplace Risk Assessment and Control Reference Manual 2000

[2] Sintef, OREDA Handbook. 1997

[3] Amendola, A., Uncertainties in Systems Reliability Modelling: Insights gained through European Benchmark Exercises. Nuclear Engineering and Design, 1985. 93: p. 215 - 225.

[4] Holicky, M. and J. Schneider. Structural Design and Reliability Benchmark Study. in International Conference on 'Safety, Risk, and Reliability - Trends in Engineering'. 2001. Malta: IABSE, Zürich, 2001. 
[5] Rouvroye, J.L. and A.C. Brombacher, New quantitative safety standards: Different techniques, different results? Reliability Engineering and System Safety, 1999. 66(2): p. 121-125.

[6] ANSTO, Summary of the Preliminary Safety Analysis Report (PSAR) for the ANSTO Replacement Reserach Reactor Facility. 2001, Australian Nuclear Science and Technology Organisation. p. http://www.arpansa.gov.au/pubs/rrrp/psar_app.pdf.

[7] Department of Health and Ageing and enHealth Council, Environmental Health Risk Assessment Guidelines for assessing human health risks from environmental hazards. 2002, Canberra: Commonwealth of Australia.

[8] Palisade, @ Risk - Advanced Risk Analysis for Spreadsheets. Version 4 ed: Palisade Corporation.

[9] Bridgestone, How to use TKPH. 2003. p. http://www.bridgestone.co.za/content.asp?id=186.

[10] Willcocks, J. and Y. Bai. Risk Based Inspection and Integrity Management of Pipeline Systems. in The 10th (2000) International Offshore and Polar Engineering Conference \& Exhibition. 2000. Seattle.

[11] Assakkaf, I., B. Ayyub, and N. Mattei, Reliability Based Load and Resistance Factor Design (LRFD) of Hull Structural Components of Surface Ships. Naval Engineers Journal, 2000. 114.

[12] Bhattacharya, J., et al. Reliability-based combination of environmental paramters for the design of novel floating structures. in 18th International Conference on Offshore Mechanics and Arctic Engineering. 1999. St. John's New Foundland Canada 1999.

[13] Cizelj, L., B. Mavko, and H. Riesch-Oppermann, Application of first and second order reliability methods in the safety assessment of cracked steam generator tubing. Nuclear Engineering and Design, 1994. 147(3): p. 359-368.

[14] Frantzich, H., Fire Safety Risk Analysis of a Hotel; How to consider Parameter Uncertainty. 1997, Lunds Universitet Department of Fire Safety Engineering: Lund. p. 65.

[15] Magnusson, S.E., H. Frantzich, and K. Harada, Fire safety Design Based on Calculations: Uncertainty Analysis and Safety Verification. Fire Safety Journal, 1996. 27: p. 305-334.

[16] Noortwijk, J.M., et al. Probability of dike failure due to uplifting and piping. in Tenth European Conference on Safety and Reliability. 1999. MunichGarching, Germany: Rotterdam,: Balkema 1999. 